\title{
Erich Fromm y Gabriel Marcel: La esperanza frustrada y la esperanza absoluta.
}

Gabriel Marcel murió el 8 de octubre pasado, cuando iba a cumplir los 84 años.

Músico, intérprete y compositor ocasional, ante todo - "la música es verdaderamente la capa más profunda y a la que pertenece en cierto modo la prioridad", ha declarado él mismo- su música es como la luz que inunda toda su obra, como el ambiente que baña toda su produción; un fondo musical que mata las aristas y que hace al mismo tiempo imprecisos los contornos, que difumina los límites. Tal vez por eso su teatro y su filosofía, por los que es más conocido, tienen ese carácter ambiguo, antidogmático y misterioso, y más que darnos la verdad — nunca poseída para Marcel; siempre indecisa- nos despiertan la inquietud de su búsqueda. Una búsqueda que ha constituido el fin de su vida.

Porque su vida es la investigación de la verdad. Por eso su obra, su filosofía en particular, se identifica con su vida misma, es el verbo de su vida. No deja de ser significativo a este respecto que, en la conclusión de su primer trabajo, ya en 1909, escribiera estas palabras sobre Coleridge, que podemos aplicar en todo su sentido a su autor:

"Quizá tuviera interés terminar esta exposición por unas palabras que recordarán bien claramente que Coleridge no ha visto en la metafísica una simple diversión intelectual, que no se ha limitado a yuxtaponer conceptos para formar un mosaico más o menos armonioso: poco importa que lo haya 
conseguido o no; sus ideas fueron su vida misma, y lo que hubo de más interior y de más profundo en su vida; y eso sólo bastaría para conferirle un verdadero interés. La evolución de su pensamiento fue verdaderamente la de una conciencia viva, preocupada de lo que hay de más inmediato, de más actual, y, hay que decirlo, de más misterioso y de más trágico en la existencia, un esfuerzo para dominar lo que era para él lo más vitalmente importante de compreneder; y hemos visto que sería inexacto pretender que recurrió a la revelación en último extremo: no vio en la religión un recurso para salir del paso, aceptable solamente porque no hubiera otra posibilidad, sino el acabamiento, la coronación indispensable de una metafísica de la que por lo demás no dudaba" 1 .

Este es su más preciado valor. El que le ha valido ser considerado uno de los cuatro grandes de la filosofía de la existencia, y el pionero, como ha señalado Paul Ricoeur, al habernos dado con su ensayo de 1925 Existence et objetivité y, un poco más tarde en 1933, con su Position et approches concrètes du Mystère Ontologique uno de esos grandes textos programáticos, como lo habian sido para la generación precedente los de Bergson Introduction a la Métaphysique y Perception du changement ${ }^{2}$.

Sirvan de homenaje agradecido estas páginas en que se pone de manifiesto la anticipación de Gabriel Marcel a Erich Fromm en su concepción de la esperanza, tema que constituye el centro de su reflexión, el corazón de toda su obra y la culminación de su filosofía. $Y$ ojalá que su pensamiento despierte en nosotros esa in-

1. Las obras de Marcel que citamos corresponden a las siguientes siglas:

EA: Etre et Avoir. Aubier. Paris 1935.

EFC: Essai de Philosophie concrète. Gallimard. Paris 1967 Edición posterior de Du refus à l'Invocation, París 1940.

HV: Homo Viator. Aubier, Paris 1963 (Nouvelle edition revue et augmentèe)

PA: Position et approches concrètes du Mystère Ontologique. Nauwelaerts-Vrin. Louvain. París 1949.

ME: Le Mystère d'être. Aubier. Paris 1951.

I Reflexion et Mystère

II Foi et Realitè

HCH: Les hommes contre l'Humain. Fayard. Paris, 1968.

HP: L,Homme Problématique. Aubier. Paris 1968.

$\mathrm{PI}$ : Présence et inmortalité. Flammarion. París 1969.

$\mathrm{DH}$ : La dignité humaine et ses assises existentielles. Aubier. París 1964.

VJ: En busca de la verdad y de la justicia. Herder. Barcelona 1967.

ERM: Entretiens Paul Ricoeur-Gabriel Marcel. Aubier. París 1968.

ST: Pour une sagesse tragique et son au-delà. Plon. París 1968.

CS: Coleridge et Schelling. Aubier. París 1971.

2. ERM. 19-20. 
quietud por la verdad y ese deseo de la luz que fueron los resortes de su itinerario filosófico.

J. H. Schaar ha escrito en su obra sobre Fromm que éste "tiene en común con los existencialistas más de lo que él mismo parece darse cuenta o de lo que está dispuesto a reconocer" " ${ }^{3}$. Esta proximidad es patente en la concepción de la esperanza, de la que nos ocuparemos, para subrayar las semejanzas y señalar sus diferencias.

El tema de la esperanza aparece en Fromm en una de sus últimas obras, La revolución de la esperànza, escrita en 1968, con motivo de la campaña presidencial de Mc. Carthy. En ella proclama Fromm la esperanza de la transformación de la sociedad americana de deshumanizada en humanista, por medio de una revolución, sin violencia, políica y social. Aquella esperanza basada en esta revolución justifican el título de su obra, y el objetivo de una y el objetivo de la otra el subtítulo de la misma: La revolución de la esperanza. Hacia una tecnología humanizada 4.

\section{Punto de partida}

Dos posibilidades se le presentan al hombre según Fromm, dos caminos que determinan la "encrucijada" en que se encuentra el hombre de hoy: el camino de la vida y el camino de la muerte. "Los individuos buscan una nueva orientación, una nueva filosofía, que tenga por centro la prioridad de la vida -física y espiritual- y no la prioridad de la muerte" ${ }^{5}$.

3. El miedo a la autoridad. Las perspectivas de Erich Fromm. Traducción de Sergio Martínez Cano. Ed. Herrero Hnos. México 1966, p. 199. No entra dentro de los límites de este trabajo un juicio global de la obra de Fromm, ni por tanto una crítica al estudio de Schaar. Pero no podemos aceptar su denominación del pensamiento de Marcel como un "desarrollo psicológico del existencialismo", junto a Jaspers, ni la solución que, según Schaar propone Marcel a los problemas de la existencia: "Marcel está muy cerca de abogar por un regreso a algo semejante al comunalismo y colectivismo primitivos" pp. 197-198. A no ser que se entienda por tal la "comunión", el amor y la esperanza "coral" de que habla en su última obra ST 209.

4. The revolution of Hope. Toward a Humanized Technology. Harper Colophon. New York, Evanston, and London 1970. Trad. de Daniel Jiménez Castillejo. Fondo de Cultura Económica. México, 1970. A esta traducción, revisada por el propio Fromm, haremos referencia con las siglas RE.

5. RE 16. A estas dos posibilidades dedica Fromm dos capitulos de su obra: el 3.0 ; "¿Dónde estamos hoy y hacia dónde vamos?" y el $4 .^{\circ}$ : “¿Qué significa ser hombre?”, que detalla el objetivo de su revolución. 
Pero para que los hombres se decidan por el camino de la vida, que es el camino de la esperanza, es necesario que el hombre reconozca el camino que conduce a la desesperación y a la muerte; un camino por otra parte que el hombre ha comenzado a andar ya, una posibilidad que es ya, por tanto, una realidad, la realidad de la sociedad industrial, "tecnetrónica", como la denomina Fromm, utilizando la terminología de Zbigniew Brzezinski. "Avanzar hacia un orden social y cultural en el que el hombre lleve las riendas depende de nuestra capacidad de enfrentar nuestra desesperanza. Antes de nada, debemos percatarnos de su existencia" 6 .

La necesidad de este reconocimiento de la desesperanza, la plena lucidez de nuestra situación actual, que puede convertirse en desesperación, hace que Fromm la subraye repetidas veces. "Sólo percatándonos plenamente del peligro que corre la vida puede €ste potencial ser puesto en marcha y llevar así a cabo modificaciones drásticas en nuestra forma de organizar la sociedad". "Hoy día existe una desesperanza generalizada en cuanto que podamos cambiar el curso tomado por la humanidad". "Los signos de desesperanza están en todas partes... No importa qué digamos o pensemos sobre la esperanza, nuestra incapacidad para obrar o hacer proyectos para la vida revela nuestra desesperanza" ?.

También Gabriel Marcel había sentado desde el principio, y ha mantenido su postura hasta el fin, la correlación entre la desesperanza y la desesperación, la coincidencia rigurosa entre las condiciones de posibilidad de la esperanza y la desesperación. Estas condiciones de posibilidad radican en la condición general del hombre de "cautividad", por razón de las servidumbres de todo género que está abocado a sufrir, aunque sólo sea por el hecho cie tener un cuerpo, y más profundamente todavía por razón de la noche que envuelve su comienzo y su fin ${ }^{8}$.

Esta situación del hombre cautivo, la formula Marcel diciendo que la esperanza se sitúa en el cuadro de la prueba. Prueba que es una situación en que el ser del hombre está comprometido, en peligro. Una situación que nos invita a desesperar. No se da la

6. RE 34.

7. RE pp. 8, 17, 33. No es válida, por tanto, la afirmación de schaar de que a Fromm "le falta el valor de la desesperanza" (O. C. p. 200) al menos desde la aparición de $\mathrm{RE}$.

8. PA, 279; EA $135 ; \mathrm{HV} 74,76$. 
esperanza, sino desde el reconocimiento de la tentación de vacío y no ser que es para el hombre su existencia encarnada. Por eso la prueba es una invitación a preguntarme sobre lo que soy, a un acto de recogimiento para reconocer el peso ontológico de la experiencia o a descubrir el ser en la existencia. Es el cuerpo - soy y no soy mi cuerpo- lo que constituye la ambigüedad esencial de mi existencia, que se mueve entre el ser y el tener, y lo que determina la definitividad o transitoriedad de la muerte.

Desde es'a perspectiva es lógica la importancia de la encarnación, dato central de la metafísica para Marcel, como lo es la posibilidad permanente de suicidio o la tentación de desesperar. Tentación y posibilidad que debe súperarse por una reflexión inseparable de la libertad. Así se comprende que la función de la metafísica sea exorcizar la desesperación, despertando en el hombre el sentido - sagrado- del ser. $Y$ que su filosofía adquiera el tono dramático de un pensamiento ( $y$ de una opción) que traen entre manos el sentido de su existencia dramática.

Es decir: tanto para Marcel como para Fromm sólo se llega al reconocimiento del ser desde la posibilidad de su negación, sólo es posible la esperanza desde la situación de desesperanza que, como veremos, equivale a la tentación de desesperación.

Sin embargo, esta tentación es de carácter sociológico en el primero y antropológico-metafísico en el segundo. Fromm hace una disección de la sociedad actual -el mundo en el que somos-en el que impera el principio del tener, de la posesión y del consumo que impone al hombre un modo de ser "pasivo" y en definitiva "necrófilo". Y en este análisis coincide con el que hace Marcel, sobre todo en su obra Les hommes contre l'humain. Los dos hablan del predominio de la técnica sobre el hombre, de la pérdida - Marcel dice falta de sentimiento- de otros valores distintos de ella, del principio de la eficacia y el rendimiento en orden a una produción más cuantitativa que cualitativa, del envilecimiento de la persona que se convierte en una máquina, en una unidad de funcionamiento, en un número reconocible por unos datos antropométricos, o expresable en tarjetas perforadas. El hombre de la sociedad tecnetrónica es un ser sin individualidad, lleno de indiferencia por la vida que llega a considerar como una broma sucia, un hombre pasivo, perezoso, sin gozo de crear, sin capacidad de decidir o actuar, falto de contactos interpersonales, muerto al sen- 
timiento. Un ser alienado o una persona sin "núcleo" espiritual ienucleación de la persona). Un hombre que tiene muchas cosas, pero que no es nada. Tanto Fromm como Marcel condenan el abuso de la propaganda que manipula las conciencias y coacciona psicológicamente a consumir más ${ }^{9}$. En una palabra: tener y no ser ${ }^{10}$.

Si no sorprende la coincidencia, en muchos casos literal, en la caracterización de esta sociedad, llama la atención la utilización de la terminología - no la significación- marceliana del Etre et Avoir que ha dado título a una de sus primeras obras y más conocidas. $Y$ es tanto más sorprendente cuando advertimos, que Fromm, tan generosamente agradecido a sus fuentes, que señala puntualmente, no cita ni una sola vez a Marcel. Como es igualmente notable la correspondencia entre la concepción frommiana de la esperanza y la del propio Marcel. ¿Habrá que decir que lo desco. noce y que es pura coincidencia?

\section{Conceppción de la Esperanza: Deseo y esperanza}

Tanto Fromm como Marcel comienzan por definirla negativamente. La esperanza no es el deseo o el anhelo. Si así fuera, "a aquellos que desean tener más y mejores automóviles, casas y artefactos eléctricos, serían individuos esperanzados. Pero no 10 son. Son gente ansiosa de consumir más y de ninguna manera gente con esperanza" "1. Ahí se queda Fromm: en un ejemplo que apunta someramente el objeto del deseo, relacionado con el mundo del tener y del consumo, y en el ansia siempre insatisfecha, insinuada como de pasada, que produce en el sujeto.

Marcel ha tratado en muchos lugares de su obra del deseo y de su relación con la esperanza. Precisamente en su Esquisse d'une phénoménologie et d'une métaphysique de l'espérance parte de una experiencia de esperanza que equivale al deseo. Pero de

9. Fromm, cap. III, y en El corazón del hombre, pp. 61-62. Marcel, sobre todo en cap. IV de $\mathrm{HCH}$. La crise des valeurs dans le monde actuel pp. 122-143. También HCH 49, 55, 72, HP, 54, 179, ME II 44, 99, DH 211 PA 256 sig:

10. Fromm utiliza esta fórmula en $\mathrm{RE} 89,90,91,92,135,148$, etc. Ya lo había hecho en El corazón del hombre, p. 41, "Tener y no ser es 10 que cuenta".

11. RE 18 “QQué significa esperar? ¿Significa acaso, como muchos piensan, tener anhelos y deseos?". 
una "esperanza diluída", "degradada", porque la esperanza verdadera es distinta del deseo y del anhelo ${ }^{12}$.

De haberlos confundido acusa Marcel a Spinoza, que ha contrapuesto el temor a la esperanza, cuando en realidad el correlativo del temor es el deseo. La esperanza incluye el anhelo como uno de sus elementos, pero lo supera, lo transciende, y se sitúa en diverso plano, en regiones completamente distintas de la vida espiritual. Son de diverso orden. El deseo es del orden del tener. La esperanza una forma del ser $^{13}$.

"Desear es de algún modo tener sin tener", una posesión sin objeto. El torbellino de temores, de ansiedad, y la tensión consecuente al orden de la posesión, junto a la separación del elemento objetivo del deseo, a la vaciedad de su objeto, son el motivo de su carácter lancinante ${ }^{14}$.

Los caracteres del deseo, son los mismos de la posesión. El deseo es egocéntrico; la esperanza, comunitaria. El deseo y el anhelo son pasivos, expresables con un potencial "je voudrais bien...", mientras la esperanza es activa, depende de un acto de voluntad libre que afirma categóricamente "quiero", aunque esta afirmación presente esté preñada de paciencia. Se desea algo eoncreto, exterior, algo que se pueda tener. En cambio el objeto de la esperanza es la salvación, la integridad: no algo exterior, sino yo mismo. Por esa concrección del objeto, el que desea vivamente consigue más fácilmente con la imaginación el objeto de su deseo. Pero, por eso mismo, es presa fácil de la ilusión, de la autosugestión, que no se dan en la esperanza, que se prohibe imaginar lo que espera ${ }^{15}$.

12. HV. 37. Tanto Marcel como Fromm, consideran necesaria esta experiencia para comprender la esperanza misma. “... faire appel a une certaine experience qu'il faut suppposer présente chez celui a qui on s'adresse". Al hablar de la dificultad de definir la esperanza, Fromm considera "imposible describirla si el interlocutor no compartiese en ninguna forma la experiencia de que se habla". RE. 23. Aunque secundario, es otro de los puntos comunes a los dos autores.

13. "L'espérance... constitue une veritable réponse de l'être" HV. 38. En el mismo sentido se expresa Fromm: "la esperanza es un estado, una forma de ser". RE. 23. Más adelante, al tratar las relaciones entre la fe y la esperanza, y el objeto de ésta, volveremos sobre este principio de ser, y no tener, que preside ambas concepciones, aunque con diverso significado.

14. EA. 196, 236. Cfr. PA. 278, EA. 107, ME. Ir. 159-161.

15. EA. 115, PA. 285, HV. 57, 84. ME II 160-162, PI. 136, 183. DH. 191. ST. 74, entre muchos otros. 
Tal vez la expresión más rotunda de la oposición del deseo y la esperanza, de la incompatibilidad de ésta en el mundo de la posesión, de la técnica, que es el mismo del temor y del deseo., la formuló Marcel en el prólogo a la obra de Troisfontaines: "es más difícil que en este mundo de la técnica haya lugar para la esperanza que el asfalto de una carretera pueda alimentar ni siquiera una brizna de hierba". La esperanza sólo podría brotar por la brecha del tener, por las fisuras del caparazón que la posesión segrega en torno a nuestro yo ${ }^{16}$.

3. La espera pasiva y el violentamiento de la realidad. Desesperanza y desesperación.

Esta pasividad, característica del deseo, vuelve a ser el punte de encuentro de Fromm y Marcel. "La esperanza es paradójica, dice Fromm. No es ni una espera pasiva, ni un violentamiento ajeno a la realidad de circunstancias que no se presentarán" ${ }^{17}$.

En primer lugar, no puede llamarse esperanza a esa especie de expectación que posee la cualidad de la pasividad y de la espera, a menos que quiera hacerse de la esperanza una envoltura para la resignación, una mera ideología. Es decir: como la ideología, para Fromm, son ideas vagas, generales, formuladas para el consumo público, que en lugar de reflejar, la realidad, la disimulan, que en vez de darnos los perfiles de la verdad los disimulan, del mismo modo la esperanza pasiva éncubre o disfraza una situación de desesperanza ¿Por qué? Porque según el patrón social el hombre de éxito no debe tener miedo, ni se siente sólo, ni aburrido: por eso esta verdadera realidad desesperanzada debe ser reprimida al inconsciente y sustituida con la apariencia de una esperanza consciente. Pero la realidad es que esta esperanza pasiva es una forma disfrazada de desesperanza y de impotencia que se halla estrechamente relacionada con una forma generalizada de esperanza que podría describirse como temporal, cuyo fundamento estaría en la idolatría del "Futuro" ${ }^{18}$.

16. TroisfontaInes, R., De l'existence a l'être. La philosophie de Gabriel Marcel. Nauwelaerts. París Louvain, 1968. p. 11 HV. 79.

17. RE 21. No se ve muy clara la paradoja. Más patente aparece en la formulación marceliana como una "no-aceptación positiva", a la que nos referiremos después. 
Naturalmente, Fromm no ignora que la esperanza está orientada, proyectada, hacia el futuro. El defecto de esta falsa esperanza está en la idolatría, en la entrega total, en el abandono absoluto, en el sacrificio del presente al futuro "No se espera que ocurra nada en el ahora, sino únicamente en el momento siguiente... en el año venidero" ${ }^{19}$. Como no se espera nada ahora, y la acción es presente, no queda sino esperar, pasivamente, el después.

Así pues, esperanza pasiva, temporal, impotencia y resignación, como fachada sólo de lo que en realidad es "desesperanza" e"impotencia" ("hopelessness and impotence").

Esta desesperanza inconsciente es la que decíamos que Fromm exigía desenmascarar, la que había que hacer consciente, como condición previa para poder hacer la revolución de la esperanza. Pero Fromm añadía una segunda condición: "comprobar la posibilidad real de cambiar nuestra vida cultural, económica y social... Si no hay tal posibilidad real, entonces la esperanza, en verdad, es una absoluta tontería" ${ }^{20}$. Este conocimiento nos librará de "otra forma de desesperanza y desesperación ("hopelessness and despair") que adquiere exactamente el disfraz opuesto, a saber, el disfraz de la frase hecha y el aventurerismo, del desprecio de la realidad y del violentamiento de lo que no puede violentarse.

Esta segunda forma, Fromm la ejemplifica en Marcuse al que presenta como un "intelectual enajenado" que presenta su personal desesperación ("despair") como una teoría del radicalismo". "Sus teorías son una ilusión ingenua, cerebral, esencialmente irracional fuera de la realidad y carente de amor hacia la vida" ${ }^{21}$.

Esta sería una falsa esperanza por falta de realismo en su acción. La esperanza verdadera, aunque unida a la fortaleza, como veremos, no desprecia la realidad. La asume, y con absoluta luci-

18. Estos son los términos que utiliza Fromm para explicar otros tipos de idolatria de la que habla a propósito del hombre, del mundo de la técnica y el consumo. Esta idolatría equivaldría a la "alienación" por la que el hombre pierde su ser y se convierte en cosa, sacrifica su ser en favor de la cosa. RE 22 . 135.

19. $\mathrm{RE} 19$.

20. RE 34 .

21. RE p. 20, nota 3 . He subrayado los dos pares de términos, que pueden darnos pie para matizar las diferencias entre la desesperanza y desesperación, considerados como sinónimos. 
dez. El que afronta la muerte con esperanza, está lejos del que, por desesperación, se arroja en sus brazos por el suicidio.

En rigor, Fromm no distingue entre desesperanza ("hopelessness") y desesperación ("despair"), puesto que la primera es término común a las dos situaciones. Pero da pié para interpretar la desesperanza como la falsa esperanza pasiva -espera-, temporal, signada de impotencia y equivalente a la resignación. Mientras la desesperación, que incluye, tal vez comó en su origen, la desesperanza (por eso van unidas) es la actitud positiva pero sin fundamento en la realidad, la acción sin realismo del aventurerismo suicida.

Podríamos concluir, por tanto, que, para Fromm, entre la esperanza sin acción, pasiva, y la acción sin esperanza; él aventurerismo, se da la esperanza activa o "la revolución de la esperanza". $O$, en la realidad, entre la desesperanza y la desesperación está la esperanza ${ }^{22}$.

Marcel había escrito ya el 10 de Diciémbre de 1931 "La esperanza es al deseo, lo que la paciencia es a la pasividad" ${ }^{23}$. Esta relación a la paciencia es la que, para Marcel define al tiempo su rechazo de la virtud de la esperanza como una espera pasiva y como un violentamiento de la realidad. Merece la pena citar lo que dice en La dignité humaine: "Si se dice, como hay que decirlo, que la esperanza es el acto por el que la tentación de desesperación es activamente superada, es preciso añadir que esta victoria no va acompañada necesariamente de un sentimiento de esfuerzo, sino que más bien está unida a una distensión más que a una tensión. Pero tengamos cuidado en esto: esta distensión ("détente") no es y no debe ser un relajamiento ("relâchement"). Es este uno de los puntos sobre los que he insistido más... He mencionado antes la paciencia, pero es evidente que esta es lo contrario de la pasividad. Tenemos que cuidarnos en realidad de las mismas con-

22. Esta revolución de la esperanzza la entiende Fromm como acción que no incluye necesariamente la violencia. El autor trata este punto en el último capitulo, donde aborda la praxis de la revolución en los Estados Unidos. En él rechaza la violencia como medio, posible por otra parte, de llevar a cabo la transformación, porque la considera como el resultado de la desesperación, la vaciedad psíquica y el odio a la vida. Cfr. p. 140 sig.

23. EA 135. 
fusiones que he señalado a propósito de la receptividad. En lo que concierne a la esperanza, nada podría ser más falso que ver en ella una especie de espera inactiva orientada hacia un acontecimiento del que se cuenta con que se producirá, si me atrevo a decirlo, completamente solo. Lo que es exacto es que la esperanza o la paciencia pueden degradarse precisamente cuando la distensión se convierte en relajamiento" ${ }^{24}$.

El texto es suficientemente expreso para que multipliquemos las citas. Marcel concibe la esperanza como una reacción activa contra un estado de cautividad, una "respuesta activa" a la tentación de desesperar, una conquista, una lucha contra ese otro yo que cada uno encuentra dentro de sí, demasiado inclinado al "abandono y la desesperación" ${ }^{25}$. Si Fromm hablaba de paradoja, Marcel ha expresado el carácter antinómico de la esperanza en la participación simultánea por parte del que espera del "don y del mérito", de la "gracia y la libertad". El don no es pura y simplemente recibido por un sujeto que no tendría más que hacerle sitio en sí. La verdad es que el don es una llamada que se trata de responder. Recibir y responder.

Marcel ha reivindicado el sentido profundo de la receptividad que no es exclusivamente pasivo. Hay que devolver a esta palabra, dice, el valor positivo que generalmente se le niega. Atengámonos a la relación compleja y precisa que apuntamos cuando decimos que un hombre ha recibido a otro en su casa: recibir es entonces algo así como el poder de asumir, de abrirse a, que incluye un elemento activo y que, en algún sentido, supone una participación de la propia intimidad y una donación de sí.

Para expresar el carácter activo de la respuesta Marcel ha creado un término "responsivité", capacidad o facultad de responder, que traduciría de modo menos inexacto la actividad opuesta a la inercia interior, que es insensibilidad o apatía ${ }^{26}$. Esta receptividad y esta responsividad reclaman la presencia de uno de los términos más fecundos del pensamiento marceliano: el de la"disponibilidad" tan próximo a otro que utiliza Fromm, el de la "vul-

24. DH 186.

25. ME II 160-161.

26. Entre muchos lugares cfr. HV, 79, EFC, 46, 137-141, ME I 134135, ME II 110. 
nerabilidad" y que también utiliza Marcel para explicar la naturaleza de la esperanza. Ser disponible es "mantenerse activamente en estado de permeabilidad" ${ }^{27}$.

Basten estos dos textos para acreditar la negación del carácter pasivo de la esperanza. Pasividad que Marcel pone en relación, también con Fromm, con el carácter temporal, y con la desespe. ranza. Para distinguir la desesperanza de la desesperación, Marcel no considera adecuados los términos de que dispone en su ler. gua. Por eso acude al lenguaje poético de Tomas Hardy y adopta su unhope que Charles du Bos ha traducido por inespoir.

Así como Fromm parece distinguir implícitamente una y otra acepción en el emparejamiento de los términos, Marcel intenta una caracterización que los diferencie. Inespoir es un estado de inquietud, de ansiedad, quizá relacionada con la angustia de la temporalidad, de sentirse embarcado en el tiempo. No es, come dirá después a propósito de la desesperación, la conciencia del tiempo cerrado, sin salida, ni, como la esperanza, tiempo abierto, horizonte, sino tiempo, sin más, en el que me hallo sumergido. Un fluir sin fluir, o mejor, sin avanzar. $Y$ como raíz: el mundo del tener, que nos hace indisponibles, la misma sociedad de consumo que, según Fromm, impone reprimir una realidad desesperanzada bajo el velo de una esperanza pasiva.

Hemos indicado la relación que pone Marcel entre esperanza y disponibilidad. Pues bien, de la indisponibilidad, del hecho de estar ocupado de sí, nace una "inquietud indeterminada" una es-

27. PA 290. Fromm adopta el término de Monseñor W. Fox de vulnerabilidad, que relaciona con la identidad, con el yo y en último término, con el ser y el tener. Una persona es vulnerable cuando se experimenta a sí misma como un "yo", como alguien que es. Por el contrario es invulnerable la que se experimenta como un yo, es decir, como una cosa que tengo (sea esta cosa su cuerpo, su memoria, sus bienes o sus opiniones y gustos RE 89, 91.

El concepto de disponibilidad a la que denomina también permeabilidad, es de fecundidad asombrosa en el pensamiento de Marcel. Lo relaciona con la admiración, la felicidad, la esperanza, la caridad, y eso significa que está en el centro de su reflexión. Por lo que hace a nuestro propósito, baste esta breve cita de su Appartenance et disponibilité; "Tiendo a hacerme indisponible en la medida exacta en que trato mi vida o mi ser como un tener de alguna manera mensurable..." EFC, 86.

No vamos a referirnos tampoco a los conceptos Frommnianos de interés, identidad o integridad, que encuentran réplica en los "coesse"., identidad e integridad marcelianos. 
pecie de "crispación" (lo opuesto a la "detente" de la esperanza) interior. Esta inquietud, se pregunta Marcel, ¿no sería la misma angustia de la temporalidad, la angustia de sentirse entregado al tiempo...? Esta angustia envuelve una inespoir que con respecto a un objetivo determinado cambia inevitablemente en désespoir ${ }^{28}$.

Años más tarde recogerá estas notas - provisionales- de su diario en su estudio sobre "pertenencia y disporibilidad" e interpretará esa ansiedad como un estado de inercia interior, en cuyo seno el mundo es vivido como estancamiento, como putrefacción, estado que traduciría admirablemente el vocablo inespoir tomado en lo que podría llamarse su "negatividad positiva" ${ }^{29}$.

Así como de la desesperanza (inespoir) sólo habla en dos ocasiones, Marcel considera a la desesperación como el contrapunto de la esperanza. Ni el temor ni el pesimismo, sino la desesperación. Es un par de actitudes que surgen de un mismó punto, de la consideración de la realidad, la vida, la experiencia, según que se afirme el ser o se le niegue. "La desesperación se presenta como la consecuencia o la traducción de un determinado balance: aunque puedo valorar la realidad (...) no descubro en ella nada que resista a un proceso de disolución que se realiza en el fondo de las cosas y que mi reflexión me permite reconocer y señalar. En la raíz de la desesperación creo encontrar esta afirmación. No hay nada en la realidad que me permita abrirle un crédito, ninguna garantía ${ }^{30}$. "Es preciso que haya ser", dice la exigencia ontológica. Pero a esta llamada del ser, el desesperado responde: no hay ser. No re-conozco el ser. No doy crédito a la realidad, no reconozco un principio misterioso, una potencia secreta capaz de superar la prueba. "La desesperación afirma la impotencia de la realidad". La desesperación es una afirmación, una declaración que sigue a un acto de conocimiento (la reflexión primera, o la contemplación espectacular) superficial, propia de una actitud de curiosidad que no llega a conocer el ser, (sólo re-conocible por la reflexión se. gunda, recuperadora, sobre la participación intuída ciegamente). Por eso puede decirse que la desesperación surge, desde la pers-

28. EA 105-106.

29. EFC, 86.

30. PA 278. 
pectiva marceliana, de una falta de realismo como sucedia en Fromm.

Por fin la "anticipación del fin", de la propia destrucción, la conciencia del tiempo cerrado por falta de paciencia, hacen de la ciesesperación una verdadera autofagia espiritual, próxima, y aproximada por el propio Marcel, al suicidio y a la traición.

En una palabra: Fromm habla de desesperanza como una espera pasiva, signada de impotencia, temporal, y de desesperación como acción que se niega a la esperanza por falta de realismo, irracional por falta de fe en la realidad y de amor a la vida.

Marcel interpreta la inespoir como ansiedad ligada a la temporalidad, como estado de inercia interior, pasivo e indolente, y la désespoir como actitud, como decisión tomada frente a una realidad mal conocida, por tratarse de un conocimiento espectacular, incapaz de ver el ser en el fondo de la realidad. Es la declaración de que no hay salida, de que no hay salvación, de que no hay liberación de la "cautividad".

Tal vez podriamos concluir con la descripción de estos dos términos - considerados en nuestro Diccionario como sinónimosconjugando los caracteres que Fromm y Marcel han encontrado en estas dos formas negativas de esperanza. La desesperanza es un estado negativo de esperanza, la desesperación es negación de esperanza. Mientras la primera es falta de esperanza por inercia, por pasividad, por indolencia, por inhibición, por impotencia; un dejarse estar en la situación de cautividad o un abandono en los brazos del tiempo (olvido del presente en aras de un futuro indeterminado), la desesperación es acción punctual, actividad cognoscitiva y volitiva, aunque sea un conocimiento falso, irreal (para el que espera desde esa misma situación) y una decisión, en consecuencia, equivocada. $Y$ frente a la temporalidad -atemporal o indefinida - de la desesperanza, la desesperación tiene carácter de definitividad en cuanto anticipación del fin. Por eso Marcel habla de conciencia del tiempo cerrado, o en una expresión más exacta, de determinación de cerrar sobre sí el tiempo y negarse -activamente- una salida ${ }^{31}$.

31. Josep PIEPER, en su obra Sobre la esperanza, distingue dos formas de falta de esperanza: la desesperación y la presunción. Pero no habla de desesperanza. Tal vez podríamos encontrar una alusión en es- 
4. Esperanza y fidelidad: paciencia. Fortaleza y esperanza.

La esperanza no es pasiva ni violenta. ¿Qué es, pues la esperanza? La paradoja continúa cuando Marcel define la esperanza como una "no-aceptación, pero positiva" de la prueba, y por ello de la rebelión, que por ser irrupción en la existencia, en la realidad, es lo mismo que violencia ${ }^{32}$. Desde esta nueva antinomia se comprenderá el estatuto de la esperanza como "no aceptación positiva", entre la desesperanza como "no aceptación" y la desesperación como "aceptación" o asentimiento definitivo de la prueba. ¿Qué signịica para Marcel esta fórmula? Responderé con palabras de Fromm para mostrar su correspondencia: "significa estar presto en todo momento para lo que todavía no nace, pero sin llegar a desesperarse si el nacimiento no ocurre en el lapso de nuestra vida... Aquellos cuya esperanza es débil pugnan por la comodidad o por la violencia, mientras que aquellos cuya esperanza es fuerie, ven y fomentan todos los signos de la nueva vida y están preparados en todo momento para ayudar al advenimiento de 10 que se halla en condiciones de nacer... Es, digámoslo así, como el tigre agazapado que sólo saltará cuando haya llegado el momento preciso" ${ }^{33}$. ¿Podrá encontrarse un ejemplo mejor de la distensión propia de la esperanza, opuesta a la crispación o a la rigidez de la desesperación y distinta del relajamiento? Tal vez el que pone Marcel: “¿Cómo no-aceptando, puedo yo crisparme, sino al contrario distenderme en esta no-aceptación? Aquí se impone una comparación con los ágiles movimientos ("souples"), sueltos, del nadador o del esquiador experto". Realmente la imagen del músculo tenso pero sin contracción, nos transporta a la idea de un espíritu activo pero sin crispación. $Y$ "si sustituimos la no aceptación por la paciencia nos acercamos de un golpe infinitamente a la esperanza". Paciencia activa, si puede decirse, que no pasividad como podrá deducirse de su etimología. No un dejar hacer o un de-

tas palabras: "Cuando hablamos hoy día de la desesperación pensamos la mayoría de las veces en un estado anímico en que se "recae", casi contra la propia voluntad. (Esta sería la desesperanza). Pero aquí entendemos por desesperación una decisión voluntaria, no un temple anímico, sino un acto espiritual. Por tanto, no es algo en que se recae, sino algo que el hombre pone". Ed. Rialp. Madrid 1961. p. 63.

32. HV. 49. Cfr. el trabajo que dedica Marcel a L'homme revolté de Camus. HV. 345-369.

33. RE 21. 
jar ser. Paciencia significa respeto a la duración o al ritmo del otro. No atropellar, no precipitar, o más exactamente, no intentar sustituir por la violencia el ritmo del otro por el ritmo propio. Por la paciencia, tener esperanza consiste en tratar la prueba como parte integrante de sí mismo y, al mismo tiempo, como destinada a reabsorberse y transformarse en el seno de un proceso creador; en confiar en la realidad, confiar en un proceso de crecimiento, de maduración, pero sin abandonarlo sino abrazándolo para favórecerlo desde dentro. Es lo que Marcel ha denominado la experiencia en formación o la conciencia del tiempo abierto, el reconocimiento de la posibilidad de un cambio en la realidad ${ }^{34}$.

Esta paciencia expresa o traduce la fe en la realidad. Porque, no puedo superar la prueba en que me encuentro o liberarme de la cautividad si me sitúo en un mundo natural, en que todo sucede con absoluta regularidad, en que lo posterior es igual a lo que antecede. Si no pongo en marcha mis potencias de asombro, de admiración y no reconozco la posibilidad de algo nuevo, reconociendo en la realidad unas potencias secretas, un principio misterioso que está en convivencia conmigo y que no puede querer sino lo que quiero, no es posible la esperanza. Sin fidelidad no hay esperanza. $O$, como ha formulado expresamente Marcel, la fe es la armadura inteligible de la esperanza. $Y$ de aquí la indisolubilidad de la fe, de la esperanza y de la caridad como conclusión más importante de su investigación filosófica ${ }^{35}$. (Más adelante mostraremos cómo en el pensamiento marceliano la dialéctica de la fidelidad se consuma en la dialéctica de la esperanza).

También Fromm habla de una conexión estrecha entre la fe y la esperanza. Tan estrecha que se necesitan mutuamente. "La esperanza es el temple de ánimo que acompaña a la fe, la cual no podría mantenerse sin la disposición anímica de la esperanza. La esperanza no puede asentarse más que en la fe" ${ }^{36}$.

34. HV. 50-51, 66, 68. ME II, 162

35. PA 260 SS., 278, 292. ME II 171, 174. "La plus importante de ces propositions, consiste, je pense, à affirmer philosophiquement, c'est-à-dire, en deçà de toute spécification théologique, l'indisolubilité de l'espérance, de la foi et de la charité". Hay que resaltar la importancia de esta aflrmación en un pensador como Marcel, tan remiso a este tipo de aseveraciones, y colocada en la conclusión de su obra, si no sistemática, sí la más sistemática y la que nos ofrece la visión global de su pensamiento.

36. RE, 24, 25, 26. 
El paralelismo es claro hasta aquí. Incluso se podría añadir, como hace Marcel, la conexión de la fe y de la esperanza al amor, con lo que la filosofía marceliana encuentra un paralelismo perfecto en Fromm.

Sin embargo, el término de esta fidelidad y el objeto de la esperanza, del que nos ocuparemos enseguida, son diferentes.

Fromm habla de una fidelidad fundamental biológica, inconsciente o racional, y Marcel se refiere a una fidelidad ontológica. Fromm habla de la fe - junto a la esperanza y la fortaleza- "como concomitantes psíquicos de la vida y del crecimiento, cualidades "no pensadas", inconscientes, del esperma y del óvulo, de su unión, del crecimiento del feto y su nacimiento". Esta fidelidad inconsciente, cual un permanente biológico, equivale a una exigencia del vivir, a un amor a la vida como orientación fundamental del ser viviente, y funda la esperanza -inconsciente como ella- del árbol con respecto a la luz, del feto que espera nacer y respirar independientemente $o$ del niño lactante hacia el pecho de la madre ${ }^{37}$.

Pero esta esperanza inconsciente, debe hacerse consciente, y para ello debe asentarse en una fe racional "que se funda en la facultad de conocer y de aprehender que penetra la superficie y ve el meollo", y que consiste en la "convicción acerca de lo aún no probado, en el conocimiento de la posibilidad real, en la conciencia de la gestación". Esta fe, precisa Fromm, aunque es conocimiento, y conocimiento profundo, no es pura y simplemente cierto, de modo que su certeza pueda traducirse en una predicción cientifica, indudable, del futuro. En cuanto conocimiento de la realidad (de la posibilidad), del presente (en estado de gestación), la fe es certeza. Pero en cuanto posibilidad y gestación incierta. "Esta es la paradoja de la fe: ser la certidumbre de lo incierto".

En virtud de esta fidelidad biológica, pero ya racional, yo puedo tener fe en una persona, que no significa sino "estar seguro de su centro, esto es, de que sus actitudes fundamentales permanecerán y no cambiarán", confiar, "en su orientación básica hacia la vida" ${ }^{38}$.

37. RE 24, 27, 30 .

38. RE 24-25. 
Gabriel Marcel habla de relación entre la fe y la esperanza. Pero esta fe no es más que la prolongación de la fidelidad ontológica desde el ser hasta el Ser. El proceso es el siguiente. En su investigación Marcel parte de la experiencia, de la vida, de la existencia. Pero para buscar el peso ontológico de la experiencia, el ser de la existencia. Este ser no es conocido directamente, por reflexión primera, porque el ser no está frente a mí, como un objeto, sino que yo participo del ser. Esta participación, que coincide con esa exigencia, es intuida ciegamente es decir "sin saber que poseo esa intuición". La exigencia ontológica es una llamada: "es preciso que haya ser". Yo puedo re-conocer, a través de la experiencia del amor, de una promesa que me exige fidelidad, el ser en el que participo ciegamente. $O$, de otra manera, responder a esa llamada del ser. O puedo negarme a re-conocer esa participación en el ser y a responder a su llamada. El reconocimiento del ser es la fidelidad ontológica.

Fidelidad ontológica es, por tanto, el reconocimiento, no teórico o verbal, sino efectivo, (activo) de un cierto permanente ontológico, de un algo que perdura y con relación a lo cual duramos también nosotros; de un permanente que implica o exige una historia, por oposición a la permanencia inerte o formal de una ley. La fidelidad es el reconocimiento de la presencia del ser. Así se hace inteligible aquella expresión, tan cargada de sentido en el pensamiento de Marcel, pero ininteligible en su escueta formulación de "diario": "Del ser como lugar de la fidelidad". “¿Cómo se explica que esta fórmula, que ha brotado en mí en un instante determinado de tiempo, presente para mí la fecundidad inagotable de ciertas ideas musicales? - Acceso a la ontología. La traición como mal en si"

La misma idea expresa meses más tarde. "Pertenece a la esencia del ser a que se dirige mi fidelidad el poder ser no sólo traicionado...".

Sólo es posible la fidelidad donde hay ser, un ser que yo tengo que re-conocer porque no se me impone con evidencia. De aquí la importancia de la libertad en el pensamiento de Marcel, que es, al tiempo que una filosofía del ser, una filosofía de la libertad, y la posibilidad de la traición como negación del ser.

Esta fidelidad funda el amor, puesto que le ofrece el permanente ontológico que garantiza la perennidad, la promesa de eter- 
nidad, que exige, por naturaleza, el amor. Sólo hay amor donde hay un "tú", que sea ser. Pero un ser que por ser finito, perecedero necesita un ser que cimiente ese amor, y garantice su pervivencia más allá de la muerte. Ese ser es el Ser, Dios. La exigencia ontológica - a la que responde la fidelidad- se prolonga en la exigencia de cohesión y plenitud, de transcendencia, cuya respuesta constituye la fe. El ser-participado, o, como dirá en su última formulación, el ser hipoproblemático que me funda parece desdoblarse en un ser hiperproblemático, aunque en realidad se corresponden o mejor se confunden; "Llego aquí a lo que hay de más oscuro, convengo en ello, en mi exposición: me refiero a la misteríosa unión que se opera entre el ser-fundamentado, el Grund, y esa plenitud aguardada, anunciada, esperada... "Este Ser funda la unidad de los seres y hace posible la esperanza, cuya fórmula perfecta es "Espero en ti para nosotros" ${ }^{39}$.

Aunque de forma resumida este itinerario puede justificar la conexión entre la fe y la esperanza que nos ha servido de punto de partida, o aquella otra afirmación muy anterior de "Position et Approches..." que habla de una "correspondencia entre la dialéctica ascendente de la fidelidad creadóra y la dialéctica de la esperanza ${ }^{40}$.

Paralelismo, pues, entre Fromm y Marcel en la conexión entre la fe y la esperanza. Pero divergencia en el significado de estos conceptos: Mientras en Fromm la fidelidad biológica funda la fe racional en la que se asienta la esperanza, la fidelidad ontológica marceliana, y la fe que la prolonga, es el fundamento de la esperanza. Esta misma diferencia se transpone en los dos, autores al objeto de la esperanza. Pero antes de abordar este tema, digamos dos palabras sobre la conexión entre la fortaleza y la esperanza.

Los dos autores hablan de "courage".

1. En primer lugar se podría subrayar que la esperanza está emparentada con el "courage", dice Marcel. Fromm escribe:

39. Cfr., entre muchísimos lugares que se podrian citar: EA. 55-56, 59-60, 66ss., 119, 138, 149, 165, 173 PA. 261, 287-289 EFC. 101, 220-259, HV. 77, 120. ME. II 7, 39, 169, DH. 160-161...

40. PA 292, Cfr., HV 120: "Si tantas almas parecen hoy sordas a la llamada de la fidelidad creadora, es que han perdido totalmente el sentido de la esperanza". 
"hay todavía otro elemento vinculado con la esperanza y la fe en la estructura de la vida: el coraje - "courage" - o como dice Spinoza la fortaleza "fortitude".

2. Marcel afirma que la "noción es mucho más ambigua de lo que suele creerse", y Fromm que "quizá fortaleza sea un término menos ambiguo" (que courage).

3. Marcel acude a esta relación entre "courage" y esperanza para diferenciarla (a ésta) del deseo.

Fromm piensa que el hombre es "fuerte porque no es esclavo de los deseos".

4. Marcel señala que lo propio de la fortaleza es "afrontar". $Y$ afrontar es de algún modo negar, o más éxactamente "neantiser", para emplear un término forjado por Sartre y que apenas tiene equivalente: significa en suma tratar alguna cosa como si no fuera o no contara. El soldado que afronta la muerte se comporta como si la muerte no contara. No se trata de negar su existencia: eso, añade, "sería hacerse ilusiones" (optimismo). "Por el contrario el coraje llega a su culmen cuando la lucidez es la mayor posible. "Esta fortaleza es el "resorte" de la esperanza". Es decir "lo que está en el orígen", "la fuerza", o "la energía" (como traduce Larousse "ressort"), de la esperanza ${ }^{41}$.

¿Como la define Fromm? Para éste "la fortaleza es la capacidad de resistir (podríamos decir fuerza para afrontar) la tentación de comprometer la esperanza y la fe transformándolas $-y$ por ende destruyéndolas - en optimismo (las ilusiones marcelianas) o en fe irracional". Una persona es fuerte y puede prescindir de ídolos, deseos irracionales y fantasías, porque está en pleno contacto con la realidad, tanto interna como externa". Es decir, conoce la realidad. $Y$ precisamente "cuando ha llegado a una plena "iluminación" (el entrecomillado es del propio Fromm), entonces es del todo intrépida ${ }^{42}$.

"Capacidad de afrontar, con la mayor lucidez, sin ilusiones

41. ME II 159-160. Los subrayados son míos, tanto en los textos de Marcel como en los de Fromm.

42. RE 26-27. Fromm habla antes de dos clases de intrepidez que no le interesan: la una porque se funda en la falta de amor a la vida, $y$ la segunda que subordina este amor a la idolatria, sea a una persona, sea a una Idea. 
vanas ni optimismo vacío, la dificultad, el peligro, la tentación. Esta capacidad sería resorte de la esperanza". ¿No sería ésta la definición común, y de cada uno, deducción extraída de las palabras que acabamos de citar?

\section{El objeto de la esperanza}

Las semejanzas entre Fromm y Marcel continúan a propósito del objeto de la esperanza.

¿Se tiene esperanza, se pregunta Fromm, cuando el objeto de la esperanza es una vida más plena, un estado de vivacidad, una liberación del eterno hastío, o cuando se persigue, para usar un término teológico, la salvación, o empleando uno político, la revolución? $Y$ Fromm asiente, siempre que esta expectación no posea la cualidad de la pasividad o de la espera, como ya diji$\operatorname{mos}^{43}$.

Estos son precisamente los términos que utiliza Marcel en su estudio sobre la esperanza. Es obvio que si nuestro filósofo condera esencial a la esperanza la situación de cautividad, su objeto sea la liberación: "aspiro a una cierta liberación que pondrá fin a esta prueba". Y continúa: El "espero" tomado en su sentido fuerte (acaba de hablar de la esperanza diluida) está orientado hacia la salvación". Y en la página siguiente se refiere a la "plenitud vivida" como lo que está sometido a la cautividad y que sería el objetivo de la liberación, y de la esperanza ${ }^{44}$.

43. RE 18 .

44. HV 38, 39. Marcel habla en otros muchos lugares del objeto de la esperanza. Entre ellos ME II 180, HV, 64, 202, 279, EA 109, 110, 116, 117, DH, 191-192, ST, 88, 306. Quiero subrayar de un modo particular la aproximación que se da entre nuestros dos autores, en el uso del término vivacidad -aliveness- que Fromm coloca a continuación de la "vida", para resaltar su carácter activo, interesado por la vida, y que Marcel propone para expresar esos mismos caracteres. "La relación etimológica que existe entre vida y vivacidad, life y liveliness, es muy instructiva, y sobre todo convendría mostrar que lo que llamamos vida en este plano no es separable de cierto interés por la vida, que, además, es esencialmente contagioso. Quien vive realmente no es sólo quien tiene gusto por la vida, sino quien contribuye a esparcirla, como a atizarla a su alrededor. $Y$ por esta razón... una persona viva aparece como esencialmente creadora. Por esta vía podemos comprender mejor cómo el poder de crear está ligado en principio a la existencia, aun cuando ésta lleve implícita la posibilidad de decaer, de transformarse en torpeza, oscura repetición, rutina mortal" (ME, I, 154).

Esta posibilidad de degeneración de la actividad creadora de la vi- 
Sin embargo las semejanzas terminan aqui. Porque el significado de estos términos es diferente para cada uno de nuestros autores. $Y$ aquí mismo, también, comienzan las limitaciones de la revolución de la esperanza de E. Fromm, impuestas por sus propios presupuestos gnoseológicos. Fromm pretende mantenerse en los límites de la esperanza histórica, como afirma Diez Alegría desde una perspectiva religioso-teológica, y en los de la reflexión científica sin dar el paso a lo ontológico o metafísico, desde un punto de vista filosófico. Se atiene exclusivamente a las posibilidades de la ciencia, pretende mantenerse en el terreno de la "psicología, sociología, y política" o, ampliando un poco el campo, o más bien especificándolo un poco más, "de la antropología, la historia, la psicología del niño, la psicopatología individual y social". Pero de ningún modo quiere acceder a "la especulación metafísica" ${ }^{45}$. Por eso su solución no desborda tampoco los límites de lo psico-social y de lo político, y, en definitiva, resulta una solución a medias, que no es verdadera solución. "En una palabra, el actual renacimiento espiritual (la humanizáción de la sociedad tecnológica, objeto de la esperanza y objeto de su revolución) está ocurriendo no tanto en el campo de la teología y de la filosofía, sino en el de las acciones y movimientos políticos y sociales. De hecho este nuevo humanismo constituye un retorno al mensaje de los profetas que no predicaron la creencia en Dios, sino que los hombres cumplieran la voluntad de Dios ${ }^{46}$.

El pensamiento de Fromm podría calificarse de vitalismo y activismo de acuerdo con su concepción de la fe y la fidelidad.

da, en rutina profesional, queda perfectamente traducida por el "tedio" que cuando se generaliza y tiñe toda mi existencia, me conduce a la desesperación" (ME, I, 177). Cfr. PA 258-259.

Paralelamente dice Fromm: "¿Se tiene esperanza cuando el objeto de ésta no es una cosa, sino una vida más plena, un estado de mayor aliveness, vivacidad, una liberación del eterno hastío..." ( $\mathrm{RE} 18$ ).

"Los signos de la desesperanza están en todas partes. Mírese la expresión aburrida del promedio de las personas..." (RE 33), o como dice Marcel "la impresión de agobiante tristeza que se desprende de un mundo organizado sobre la función (PA 258).

Es decir que para Marcel, la vida plena equivale a la liberación del tedio que abruma a los hombres que viven en un medio tecnificado que gira en torno de la función (PA 258) y que viene a desembocar exactamente en la desesperación. Exactamente Fromm, que habla también de los "signos de desesperanza de este mundo tecnetrónico, que se traducen en la expresión aburrida del promedio de personas" ( $\mathrm{RE}$ 33).

45. RE 10, 66, 67. Cfr. Diez-Alegria, José Maria. Yo creo en la esperanza. Desclée de Brouwer, Bilbao 1972, p. $130 \mathrm{~s}$.

46. RE 138. 
En efecto: todo el pensamiento frommniano gira en torno a la vida. La vida es el criterio del bien y el principio de todo valor. "La ética biófila tiene su propio principio del bien y del mal, había escrito en El corazón del hombre. Bueno es todo lo que sirve a la vida, todo lo que fortifica la vida, el crecimiento, el desarrollo". "La vida, escribe en El miedo a la libertad, sólo tiene un significado: el acto mismo de vivir". "Todo ello significa que lo importante aquí es la actividad como tal, el proceso y no los resultados" ${ }^{47}$.

Y fiel a este vitalismo se mantiene en La revolución de la esperanza. "El sistema de valores correspondiente al punto de vista presentado en este libro se funda en el concepto de lo que Albert Schweitzer llamó la reverencia pör la vida. Valioso o bueno es todo aquello que contribuye al mayor despliegue de las facultades específicas del hombre y fomenta la vida" ${ }^{48}$.

Amor a la vida como principio de la revolución, vida plena y vivacidad como objeto de la esperanza.

Una actividad y una vida que deben desenvolverse en dos planos para sarlo plena y verdaderamente: el supervivencial, en el orden físico o biológico, y el trans-supervivencial, en el psicoespiritual. Es la doble respuesta a una necesidad doble del hombre. Porque el hombre siente un impulso intrínseco a sobrevivir físicamente, pero, sobre todo, en la esfera característica del hombre, "transutilitaria" o de la transsupervivencia, "el hombre quiere comprender qué es la vida humana". "El dinamismo de la naturaleza humana, en la medida que es humano, se halla arraigado primariamente en esta necesidad del hombre de expresar sus facultades en relación con el mundo más que en la necesidad de usar al mundo como un medio para satisfacer sus necesidades fisiológicas". "Los impulsos del hombre, recalca, en cuanto son trans-utilitarios, expresan una necesidad fundamental y específicamente humana: la necesidad de relacionarse con el hombre y con la naturaleza, y de afirmarse en esa relación" ${ }^{49}$.

47. El corazón del hombre. Trad. de Florentino M. Torner. Fondo de Cultura Económica. México. 1970, p. 48. El miedo a la libertad. Trad. de Gino Germani. Ed. Paidós, Buenos Aires 1971. pp. 306, 307.

48. RE 94 .

49. RE 75-76. 
Fromm se extiende en este tejido de relaciones intersubjetivas, "experiencias humanas típicas", como el amor, la ternura, la compasión, el interés (inter-esse), la responsabilidad, la identidad y la integridad, la vulnerabilidad, la fe, la esperanza, el coraje, y el fenómeno que subyace ${ }^{50}$, implicitamente a los conceptos que hemos mencionado, y que fromm examina brevemente: el de la transcendencia ${ }^{51}$.

Sin embargo, aunque Fromm utilice términos tales como supervivencia y trans-supervivencia, aunque recoja las definiciones de hombre dadas por los filósofos, aunque defina la fe como conocimiento del "meollo", e incluso cuando, a propósito de la exigencia de transcendencia o de la renovación psico-espiritual programada en su humanismo, aflore la problemática réligioso-teológica, por fin, aunque juegue con los términos ser y tener, - “la base del amor, la ternura, la compasión, el interés, la responsabilidad y la identidad es precisamente la de ser versus tener" - hable de esencias y de participación en el ser, todo eso no son más que intentos sofocados por su decisión de atenerse a los hechos y de obtener en sus conclusiones afirmaciones de carácter científico.

"Esta revolución cultural deben empezarla y llevarla adelante todos aquellos para los que la vida, y no las cosas, es el valor supremo, haciendo a un lado sus particulares conceptos filosóficos y. religiosos" 52 .

Este principio de vida hará que el hombre en su actividad económica necesaria para su supervivencia, no se subordine a la eficacia y el rendimiento, sino que atienda a su crecimiento y. desarrollo personal; y que el hombre pasivo y manipulado por la sociedad de consumo se transforme en una persona activa, responsable y crítica. Este principio presidirá, finalmente, la revolución cultural, que tiene como meta la creación de un hombre nuevo cuya meta en la vida sea ser y no tener y usar.

Todas estas transformacioens equivalen a la vida plena y a la

50. El traductor escribe "sustenta". Creemos que "subyace" expresa mejor el significado de "underlies". El fundamento que sustenta, como añade a continuación, es el ser.

51. RE 80-92.

52. RE 91, 92, 135, 147-148. 
vivacidad, objeto por tanto de su esperanza. Aunque hable de ser. Por "estar vivo - plenamente, pero sin más- es", dice Fromm. $O$, lo que es lo mismo, ser equivale a vivir. "Salvación de la enfermedad y la locura", que amenazan la vida biológica y psiquicamente. "Liberación del egoísmo y la soledad" que son las consecuencias del tener, de la alienación, de la no-identidad en que cae el hombre de la sociedad tecnológica. Se trata, para Fromm, de que el hombre viva. Supervivencial y transsupervivencialmente. Este es el objeto de la esperanza, y el principio de su revolución ${ }^{53}$.

Pero vivir es morir. Fromm reconoce que el precio que el hombre paga por su conciencia, en ese afán y en esa necesidad de comprender el sentido de la vida, es la inseguridad. Inseguridad que nace, paradójicamente, de la única certeza que posee. "La única predicción cierta que puede hacer es: Moriré" ${ }^{54}$. ¿Cuál es el sentido de la vida ante el hecho indudable de la muerte? Aquí reside, podemos afirmar con Moltmann, el auténtico problema de todo pensamiento de esperanza.

Fromm no responde. $Y$ por tanto, ese impulso trans-supervivencial queda frustrado, esa necesidad de sentido no es satisfecha. "Unicamente allí donde la muerte es devorada en la victoria, queda superada la última y auténtica no-identidad del hombre", dice Moltmann citando a Bloch. Porque la salvación no es nada si no nos libra de la muerte", como ha dicho Marcel, y ha recogido Pieper. "Esta última expresión de la obra de Gabriel Marcel me parece evidente, mientras que nó comprendo una palabra de las que dice Ernst Bloch sobre el tema.

O sea, que la certeza de la conciencia de clase es un novum contra la muerte, un antídoto contra la muerte. Es cierto que no muere la clase, como tampoco la sociedad, ni el "cosmos", ni la "evolución". Lo único que padece la muerte es el individuo. Mas es ahí, precisamente, donde tiene su fundamento el insoslayable orden y donde han conectado muerte y esperanza entre sí. Es ab-

53. RE 48, 68, 88, 89, 91, 148. "Considerada superficialmente la gente parece llevar bien su vida económica; sin embargo sería peligroso no percatarse de la infidelidad profundamente arraigada que se oculta detrás del infierno de bienestar. Si la vida pierde su sentido porque no es vivida, el hombre llega a la desesperación. Nadie está dispuesto a dejarse morir por inanición psíquica, como nadie morirá calladamente por inanición física". Cfr. El miedo a la libertad, p. 300 .

54. RE p. 68 . 
surdo pensar que una colectividad (especie humana, universo o naturaleza) sea capaz de esperar; en todo caso sería un empleo impropio e inadecuado del término. En sentido estricto, la esperanza, lo mismo que el morir, sólo existe como acto personal" 55 .

¿De qué sirve la fe y el amor a la vida ante el hecho incuestionable de la muerte? Más que fundamento de esperanza, como pretende Fromm, se convierte en principio - al menos tentaciónde desesperación. Amo la vida que perderé irremisiblemente. Y porque la amo y cuanto más la ame, más dolorosa será la pérdida, y mayor la tentación de desesperar.

Goldbrunner ha escrito: "El hombre está sentado ante un muro de piedra, sin salida ni por la izquierda ni por la dérecha, ni por arriba, ni por abajo, ni por el medio; sólo es posible el movimiento de retorno a la propia interioridad. En este proceso de muerte en que todo se abandona y en la experiencia de la falta de salida y de esperanza puede surgir una nueva dimensión, un cambio cualitativo repentino, un salto no biológico ni psíquico sino ontológico. En términos filosóficos esto sería el abandorio y la muerte de los entes todos a fin de conseguir el contacto con el ser. ¡Del ente al ser! iDe las criaturas al principio fundamental!" 56.

Este salto ontológico es el que no ha querido dar - según sus palabras - o no ha sabido ver Fromm. $Y$ el que ha dado Marcel ${ }^{57}$.

Marcel también se ha preguntado por el sentido de la vida, incluso, se ha propuesto, como hipótesis, el vitalismo con que Fromm responde a esta pregunta. "¿Por qué no decir que la respuesta a la pregunta ¿Quién soy yo? es mi vida". En tres momentos se enfrenta Marcel con este problema: en el comienzo de la década de los años 30 , al final de esa misma década y en sus lec-

55. Moltmann, J., Theologie der Hoffnung: Teologia de la Esperanza. Trad. de A. P. Sánchez Pascual. Ed. Sígueme, Salamanca, 1969, p. 453, 455 y ss. PIEPER, J., Esperanza e Historia. Trad. de Diorki, Sigueme, Salamanca, 1968, p. 85-86. Cfr. O'Collins, G., Man and his new hopes, El hombre $y$ sus nuevas esperanzas, Trad. Antonio Diego, Sal Terrae, Santander 1970, p. 174 y ss. p. 372 .

56. J. GoldBRUnNer, Qué es desesperarse, Concilium, 59 (nov. 1970),

57. El interés y la preocupación por el ser quedaría patente con sólo los titulos de sus obras: Journal Métaphysique, Etre et Avoir. Position et Approches concrètes du mystère ontologique, Homo Viator: Prolégomenes à uné métaphysique de l'espérance, Le Mystère de l'être. 
ciones en la Universidad de Aberdeen, en mayo de los años 49 y 50, que dio como fruto El misterio del ser. En la primera de esas ocasiones, en 1930, Marcel se manifiesta con energía contra esa especie de filosofía informulada y difusa, la filosofía de la vida, que propone a la vida como "único criterio o referencia de valores" o como "el principio de todo valor", y que mantiene como un axioma la equivalencia entre mi ser y mi vida: "yo coincido con mi vida, yo soy mi vida". "De este conjunto de consideraciones yo extraeria únicamente esta conclusión: que no hay salvación para la inteligencia ni para el alma, más que a condición de distinguir entre mi ser y mi vida". Por eso unos meses después, en Marzo de 1931, escribirá en su diario con una seguridad inusitada en él: "Es sin duda metafísicamente falso decir que yo soy mi vida" ${ }^{58}$ :

Marcel rechaza este vitalismo por la ambigüedad del concepto de vida y porque, en un acto de recogimiento yo puedo tomar posición frente a mi vida, puedo juzgarla, evaluarla, rechazarla. $Y$ en estos actos aparece el intervalo entre mi ser y mi vida, su distinción, porque este juicio y esta valoración sólo es posible sobre la base de lo que soy. Soy antes de vivir. Mi ser está amenazado desde el momento que empiezo a vivir. $Y$ hay que salvarlo. Mi ser está en juego y el sentido de la vida quizá resida alli ${ }^{59}$.

Aun permaneciendo fiel en lo fundamental a esta primera formulación, Marcel suaviza sus expresiones en 1939 - "No es del todo verdad que yo soy mi vida" - y en 1949, en Le Mystère de l'être, en el cual, recogiendo la fórmula de Position et Approches... añade: "Me parece que hoy introduciría alguna moderación en estas fórmulas. No es verdad, en efecto, decir pura y simplemente: yo no soy mi vida; como dice uno de los personajes de uno de mis últimos dramas (se refiere a Antoine, uno de sus portavoces, en L'émissaire): si y no, es la única respuesta cuando somos nosotros los que estamos implicados; hay que decir al mismo tiempo que soy y que no soy mi vida" ${ }^{60}$.

Es la ambigüedad misma de la existencia encarnada, a cabaflo entre el ser y el tener o el no - ser como el cuerpo, que confiere

58. EA. 284-291, 103. ME I. 169. PI. 117, 132.

59. PA. 273-274, 276.

60. EFC. 120, 258. ME I 151-152. 
a la filosofía marceliana el carácter dramático, esencial a toda filosofía de la existencia.

Yo soy mi vida frente a la posesión, egoista y caduca, de una vida que se consume y se agota como cualquier otra posesión. Pero soy la vida plena que aspiro a vivir, a que debería vivir para ser más plenamente yo. Marcel ha hablado, en su Esquisse d'une phénoménologie de l'avoir de la posibilidad de sublimar la posesión devoradora y de transformarla en ser, a condición de mantenernos, no pasivos o inertes respecto al objeto poseido, sino activos, utilizando esas posesiones como la materia misma de una creación permanente ${ }^{61}$. Yo soy mi vida cuando la vida es activa, vivacidad, interés por la vida, cuando contribuyo a esparcirla y valga la redundancia, a avivarla a mi alrededor. Es decir cuando mi vida es como la materia de una creación. Entonces yo me transformo en una "persona esencialmente creadora".

Es entonces también cuando se ama verdaderamente la vida. Un amor que falta en el mundo de la función de hoy, porque falta el interés por la vida y se persigue el goce instantáneo, porque se han cerrado las vías a cualquier novedad, a todo misterio y a todo milagro, y se ha encerrado el hombre en el torno de lo cotidiano, de lo natural y de la posesión. "Se ha roto, acusa Marcel, un cierto lazo nupcial entre el hombre y la vida" ${ }^{62}$. Falta el ser que confiere a la vida un determinado carácter sagrado.

Pero cuando la vida es la vida a que aspiro, ya no soy mi vida. Mi ser es más que mi vida. $O$, como dice Marcel, mi ser es mucho más que mi ser. Porque en el fondo de mí mismo hay una realidad que me desborda, una realidad superior que es más yo mismo que yo mismo. Un ser que descubro en la medida que tomo conciencia más o menos distinta de la unidad subyacente que me religa a otros seres cuya realidad presiento ${ }^{63}$.

"Es preciso que haya ser". Es la exigencia ontológica. Una llamada a la que se trata de responder. La respuesta a esta llamada, la afirmación del ser, es lo que Marcel denomina la fidelidad ontológica.

61. EA 240-241.

62. ME I 152, 154, $178 \mathrm{HCH}, 139-140$. PA 256 ss.

63. EA 244. ME II 20, 39. 
Por esa fidelidad ontológica se puede afirmar que la filosofía de la existencia de Marcel es una filosofía del ser, frente al vitalismo de Fromm y su fidelidad biológica. "Puedo decir que la reflexión sobre el ser está en el centro de todo mi pensamiento desde el principio" declaraba Marcel en 1958 ante la Sociedad Francesa de Filosofía. Este ser es el que da sentido a la vida. $Y$ el que transciende la muerte ${ }^{64}$.

No se ha resaltado suficientemente el papel de la muerte en el pensamiento de Marcel. $Y$ sin embargo ocupa el mismo papel central del ser, del que no es sino otra formulación, expresada en 1951. "El problema, el único problema es el propuesto por el conflicto entre el amor y la muerte" 65.

Marcel sufrió a los cuatro años una conmoción profunda y duradera por la muerte de su madre, que déspertó en él una inquietud, la del futuro de los muertos, y que le condujo a la determinación, tres o cuatro años más tarde, de buscar una respuesta a esa pregunta. "Más tarde trataré de saber". "Y creo que sería un error minimizar la significación de esta palabra de niño: en cierto modo fijaba mi destino" ${ }^{66}$.

Marcel reconoce, como Fromm, que la única certeza que el hombre tiene es la de la muerte. La vida se asemeja a una serie de sorteos, de los que unos han tenido lugar ya, mientras que otros números deben salir aún. ¿Cuáles? ¿Cuántos? ¿Hasta cuándo se prolongará esta loteria? "Todo esto es problemático desde el instante en que he sido admitido a participar en esta lotería, me ha sido entregado un billete en el que figura una sentencia de muerte. El lugar, la fecha, el modo de ejecución están en blanco". Sin embargo, y en medio de todas estas incertidumbres: "una seguridad permanece invariable, una única proposición es indudable, moriré. La muerte es lo único no problemático de todo lo que me espera" ${ }^{67}$.

64. ST. 77. Lo mismo escribia en su $D u$ refus a l'invocation cuando, en una primera mirada hacia atrás, se encuentra dominado por dos preocupaciones, vertidas, una en la filosofía: la exigencia de ser, la otra, en el teatro: la obsesión de unos seres considerados en su singularidad. EFC. 220-221. Cfr. también EFC 102, PI. 104.

65. PI p. 82.

66. DH 43.

67. EFC 210-211, ST 72, 182-183. 
Marcel se ha prodigado en todas sus obras sobre esta experiencia existencial irrecusable de la inmanencia de la muerte a la vida, que ésta lleva en si como la "tríste mitad" en expresión del poeta de cimitière Marin, y que nadie ha formulado mejor que Heidegger con el Zum Tode Sein ${ }^{68}$.

Pero Marcel, a diferencia de Fromm, no sólo reconoce esa certeza, sino que se enfrenta con ella. No para dejarse absorber, en un pensamiento mortalista, como algunos le han acusado, que consistiria en afirmar el carácter último de la muerte, sino para reconocer primero la seriedad que le niega cierto espiritismo y $\sin$ la cual la vida sería un espectáculo de marionetas, y para transcenderla después, salvando así el sentido de la vida comprometido desde su comienzo ${ }^{69}$.

Marcel reconoce que la muerte, que nos amenaza en todo instante con engullirnos definitivamente, es la que funda el carácter trágico de la existencia.

Pero Marcel transciende la muerte con su filosofía del ser, que es una filosofía de la libertad.

"Si se puede hablar de un contrapeso ontológico de la muerte, este no puede ser ni la vida misma - tan inclinada a pactar con lo que la destruye-, ni una verdad objetiva -que en relación a lo existencial continúa siendo un más acá, un adiaforetón-. El contrapeso ontológico no puede radicar más que en el uso positivo de una libertad que se transforma en adhesión, es decir, en amor. Pero a un mismo tiempo, la muerte no sólo es contrapesada sino transcendida" ${ }^{70}$.

La salvación está en la filosofía, en la reflexión segunda, en el "recogimiento" en que yo reconozco el ser —_ "de ahí el valor sacralizante de este recogimiento-, y lo afirmo libremente. Esta afirmación de ser constituye, ya lo hemos visto, la fidelidad ontológica. Y esta afirmación del ser transciende la muerte. Si mi ser es más que mi vida, aunque mi vida termine, mi ser permanece más allá de la muerte. Por eso la opción por el ser, el permanente ontológico afirmado en la fidelidad ontológica, es opción por la in-

68. Entre otros, cfr. EFC 120, ME II, 147-166, HP, 145-146. VI 84-85.

DH 187-8, ST, 72, 175-191, 300, etc.

69. ME II 147.

70. EFC. 215, Cfr. VJ 83-84. 
mortalidad. $Y$ así puede afirmar Marcel que "en el terreno de la inmortalidad se sitúa la opción metafísica definitiva ${ }^{71}$.

Hemos hablado de opción, de adhesión y de amor. Por aquí entramos en una tercera formulación del problema central del ser o del conflicto entre el amor y la muerte. Dice Marcel que "su investigación filosófica ha estado orientada desde el comienzo hacia la elucidación de lo que se designa comunmente por la expresión existencia de Dios e inmortalidad del alma" ${ }^{22}$.

En el comienzo de su itinerario filosófico Marcel ve-desde fuera todavia- en la religión, una solución al problema de la muerte, y por tanto, un sentido a la existencia. Pero él buscaba esa seguridad existencial más acá de la revelación. "Me esforzaba por encontrar en la participación en el ser el principio mismo de la $\mathrm{fe}{ }^{73}$. Y lo encontró en la fidelidad. "Espero conseguir hacer ver cómo la fidelidad, aprehendida en su esencia metafísica, puede aparecernos como el único medio de que disponemos para triunfar eficazmente del tiempo" ${ }^{74}$.

La exigencia ontológlica, inłuida ciegamente en la participación y reconocida en la fidelidad ontológica, se transforma en la exigencia de transcendencia, más acá de la revelación, en el terreno filosófico, cuya respuesta equivale a la fe. El ser afirmado libremente en la fidelidad, es el mismo Ser al que me adhiero por la fe. El problema de la inmortalidad es el problema de la existencia de Dios.

Tres formulaciones: exigencia de ser, conflicto entre el amor y la muerte, existencia de Dios e inmortalidad del alma, y un único problema, que para Marcel es misterio: el misterio del ser, que responde al sentido de la vida.

Ahora podemos comprender el significado de los términos que Marcel, como Fromm, utiliza par expresar el objeto de la esperanza. La vida plena en cuanto plenitud, pleroma: la vida que aspiro vivir más allá de la muerte. Liberación de la cautividad, constituida por la ambigüedad esencial a la condición humana por el hecho de

71. ME II, 152.

72. "Existencialisme et pensée Chrétienne". Temoignages. XIII mai 1947, p. 162.

73. DH 41.

74. EFC 228. 
tener un cuerpo, en la opción por el ser, que es más que la vida y que, por lo mismo, transciende la muerte. Salvación de la muerte como opción metafísica fundamental.

\section{CONCLUSION}

Dos concepciones de la esperanza que se corresponden, pero diferentes; paralelas, pero a diverso nivel; terminológicamente equivalentes, pero de significado distinto.

Tanto Fromm como Marcel coinciden en afirmar que la esperanza sólo es posible desde la conciencia de una situación real de desesperanza o desde la tentación de desesperación: la sociedad tecnológica del tener y el usar, pero que para Marcel es el reflejo de la esencia o, como él gusta de decir, de la condición misma del hombre de ser encarnado.

La esperanza - difícil de definir y de comprender sin la ayuda de la experiencia - es, para ambos, una forma de ser, una actividad o una virtud, no un estado -lejos por tanto de la pasividad del deseo-, fundada en la fe en la realidad, que respeta sin violencia y asume con entera lucidez y sin optimismo vacío pero con valor, con coraje, y que se orienta a la liberación de esa situación, a la salvación de la desesperación que me amenaza, a la plenitud de vida.

Pero mientras para Fromm la forma de ser es una forma de vivir -la esperanza es una cualidad esencial a la vida- y la fe en la realidad es una fidelidad "a nuestra orientación básica hacia la vida" y la liberación o la salvación lo son de una vida no plena para conseguir la plenitud de vida, para Marcel la esperanza es realmente una forma de ser y su fe en la realidad es fidelidad ontológica y fe en el Ser para alcanzar la liberación del no-ser, la salvación de la muerte y la vida plena en la plenitud del ser. Fromm se mueve en un plano psico-biológico. Marcel ontológico. En ese ser, que es el Ser, encuentra Marcel una "seguridad existencial original que tal vez, en definitiva, sólo es una irradiación muy misteriosa del "gaudium essendi": y esta irradiación es la esperanza", y la esperanza absoluta ${ }^{71}$.

\section{Gaspar García Abril. Mayo, 1974.}

71. ST. 74. 